\title{
Cultural cooperation
}

Alfons Martinell Sempere

\section{Cooperation as human activity}

The concept of cooperation has many meanings and interpretations that have been incorporated into human activity since time immemorial, in another step of our evolution from the first social organisations up to the structure of contemporary societies. We could say that cooperation is at the heart of the human condition and socialisation. In order to ensure their needs and integrity, people require highly varied cooperation processes that match the level of development and characteristics of the activity. Every community is formed under the principle of cooperation, which takes on different aspects depending on the field or sector in which it is applied.

Cooperation enables us to survive and develop all our human potential which we would not achieve as individuals. The first social structures, such as families or clans, are cooperation-based structures which expand to other groups and organisational levels in each context and in each time period.

In an excellent work reflecting on contemporary society, the sociologist R. Sennett analyses the human processes of socialisation and the processes of human activity. In his trilogy, which begins with The Craftsman, he presents an excellent panorama for understanding the configuration of cultural actions and activity.

- Cooperation lubricates the machinery needed to make things and co-participation can compensate for that which we perhaps lack as individuals.

- Cooperation as a skill requires individuals to have the ability to mutually understand one another and to respond to the necessities of others in order to act together. But it is a thorny process, full of difficulties and ambiguities, and it often has destructive consequences.

- Cooperation could be defined as an exchange in which the participants benefit from the meeting.

- Cooperation increases dialogue skills.

- Modern society has weakened cooperation in various ways. The most direct of these weaknesses is related to inequality.

- We are losing the cooperation skills required to function in a complex society.

A first level of reflection concerns the idea that cooperation forms part of everyone's relationship with culture. 
When talking about cooperation in culture, even though it may seem obvious, we must consider its own peculiarities and its relations with other human activities, seeing as it is at the core of the social function of the individual. Exercising cultural management forms part of cooperation as a human activity.

\section{Cooperation in basic cultural activity}

All cultural acts that are handed down, in the family or in the community, from tradition or history are the result of a more or less successful cooperation process between generations. Likewise, all cultural expressions require a cooperation process between people and groups. Creativity, although it is perceived as an individual process, has a preliminary and subsequent cooperation phase that influences its results. The processes of education and the acquisition of skills in expression and creativity are actions that occur prior to the cultural manifestation, seeing as we could consider education as a very broad cooperation process. On the other hand, cultural works require cooperation for the processes involved in their exhibition, sale, promotion, maintenance, etc.

Culture invites cooperation on many levels, some of which are spontaneous and others which are a product of intentionality, with the purpose of improving individual possibilities and sharing one's values or expressive processes with others.

Firstly, all people require, in the satisfaction of their cultural needs, different kinds of cooperation processes depending on their lifestyles. Similarly, all communities structure their cultural lifestyles around an ample system of cooperation interactions in order to organise themselves and build a common cultural life.

Communication between people is essential for sharing values, lifestyles and symbolic representations which favour a sense of belonging and collective identity.

Cooperation is essential in processes of expression, by way of the various artistic languages, thus achieving its own end which is communication.

In order for cooperation to reach levels that can satisfy needs and expectations, it requires cultural management that incorporates this factor into its activities. The management of culture is the management of different classes of cooperation.

\section{Cultural life: a space for cooperation and the guarantee of cultural rights}

The Universal Declaration of Human Rights and the International Covenant on Economic, Social and Cultural
Rights define "participation in cultural life" as a fundamental right which must be protected and guaranteed to its fullest extent. See Article 27 and Article 15 respectively.

This right has become a principle which cultural management must take onboard as a primary social purpose for its function. Individual or collective participation in cultural life requires a set of interactions and organisational processes which incorporate the available resources and lifestyles, which in turn involve different social subjects.

Cultural life can be understood as the primary level of social function of a community, city, society or state in which individuals cooperate and share with their peers a great variety of expressive experiences and creative phenomena, leading to a collective memory or lifestyle. Cultural life is configured as the result of interactions occurring between individuals or social groups, as carried out in order to satisfy their own cultural needs through cooperation processes.

Cultural life represents the expression of a social group, community or society, passing through tradition and collective memory with the topicality and contemporaneity of a certain moment in a given context. It is manifested in various forms, actions, languages, organisations, businesses, industries, systems, etc. and it is characterised by its own diversity and internal complexity.

Cultural life is produced between people, communities and social interactions in cohabitation processes as a human process that has the aim of satisfying cultural necessities, a sense of belonging and the desire to share common heritage with others.

These processes take place via a set of actions and activities with goals and objectives that require specific individual or community management with the intention of satisfying cultural expectations. This management may take place in private or in one's public life, at an individual level, at a group level or in the entire population, depending on the different states and situations.

For the full unfurling of cultural life, it is important for the persons and social groups to assume their role as subjects, so as to be involved in and manage said processes. The broad range of interactions and cooperation between people and groups shows the social nature of cultural life and the level of democratic participation in these matters within a certain context.

Cultural life which brings together people, groups, organisations and institutions cannot be developed as a right without a level of cooperation with different dimensions, levels and fields. 
The organisation of cultural life, as a response to the needs of people and communities, requires the establishment of cooperation systems via the organisation of intermediary spaces and instruments, the establishment of codes of cohabitation, and the installation of conflict regulation systems that allow high levels of cooperation. rights.

Cooperation allows us to develop human and cultural

\section{Cooperation in the contemporary cultural system}

Nowadays, the broad concept of culture, or cultural management, cannot be understood without accepting that our complex societies have been configuring a cultural system as a social sub-system that interacts with other systems within the complex workings of contemporary society.

Accepting this fact alters the traditional discourses that understand culture only as the cultural policies or the cultural sector, i.e. from a socio-economic perspective. The cultural system is much more extensive than the traditional governmental cultural departments and it is inscribed into a set of practices, instruments and elements that directly affect the cultural life of citizens.

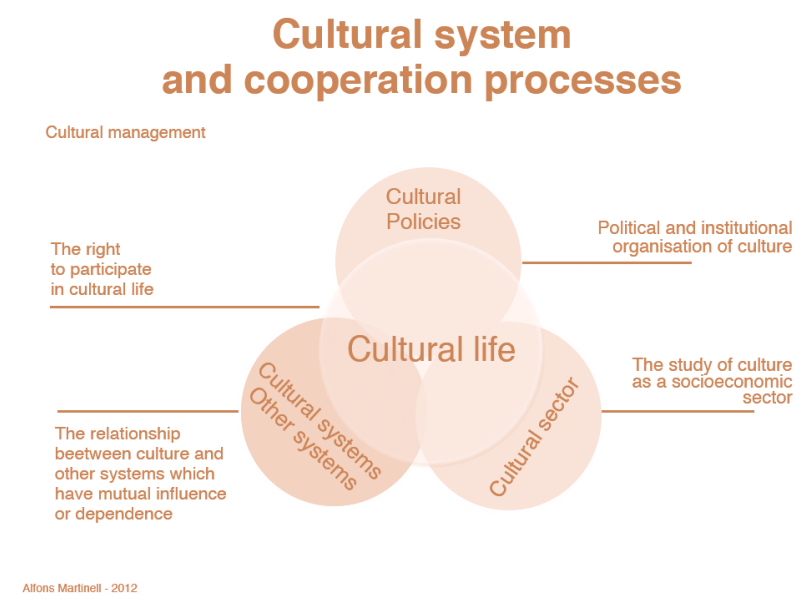

Fig. 1

At present, we accept that culture forms a very extensive system with various sub-elements and instances that interact with each other, generating a broad flow of relations. As established by the theory of systems, when there is more interaction and cooperation between the different elements of a cultural system, it becomes more coherent, wide and extensive, thus ensuring its existence (or subsistence) in a broader context.

Cultural systems require their various actors or agents to cooperate closely as a factor of survival and full development.

Cooperation in the creative-expressive process. Cooperation in production-dissemination

There are always high levels of cooperation in the course of an expressive-creative activity. They make it possible and enable it to achieve all of its purposes. Despite creation being very often considered as an individual and isolated action, reality reveals the large number of interactions and collaborations that make it possible. These are started in a prior stage, perhaps during the learning process that is a requirement for the creation's execution and potential dissemination.

The basis of contemporary creation in general, but more significantly in that which requires a complex production process (music, film, theatre, etc.) is permanent cooperation between different roles. Co-production, in its modern sense, is the most obvious expression of the union between management and cooperation. Furthermore, the mise-en-scène of various creations (theatre, concerts, dance, editing, etc.) is founded on cooperation between various people in order to produce the final result. For example, a concert is the result of an individual's work but also of the very extensive cooperation efforts made in the rehearsals. This is the reason why cooperation forms part of the fundamental core of cultural processes. Cultural management is the force between these processes and takes on different functions based on the characteristics of each action. The idea of cultural design is inscribed in the coordination between the various participants who are involved in a large network of cooperation that produces an established final objective.

\section{Cooperation and the political system}

The governance of culture is organised from community-level departments up to state structures, depending on each country's configuration of political structures and its history. We mustn't forget that in all political processes, the cultural dimension is very important as an element that fashions a way of living together.

The modern, democratic political system is organised around the definition of levels of responsibility that interact and cooperate with each other in order to produce the 
objectives and values of a society. We could say that a political system becomes more democratic when a formal organisation of cooperation relationships is established between the various units of which it is composed. Local, regional and national levels of political representation assume their duties in the cultural system in accordance with the constitutional bases and the state's legislation model.

Within this framework of cooperation, the state must maintain relationships with the private sector, civil society and other social actors.

\section{Territorial cultural cooperation}

Territorial cultural cooperation is the result of a set of practices and functions that are motivated by three factors:

- The influence of the structure of the representational political system which attributes certain functions and competencies to the various administrative levels in the field of culture. In recent years in Spain, systems have been created, based on its legal framework, for cooperation between the central government, autonomous communities, provincial councils and town councils (called counties in some areas). In order to achieve their objectives, certain levels of cooperation are required between the various administrations and this occurs through a large number of instruments. These include simple subsidies, contracts and co-organisation, up to the creation of large-scale, stable conventions. This type of cooperation is based on the collaboration necessary for the minimal establishment of the public administrative structures in the field of culture. This is based on the principles and values of the fundamental legal frameworks. The ultimate goal is to guarantee cultural rights and access to culture, based on territorial compensation systems or a countermanding of the function of the cultural market.

- The discursive ability of the various cultural agents in a territory (neighbourhood, city, county, region or country). This is needed for mutual recognition and cooperation in the achievement of their objectives and needed to harmonise the range of cultural activities of the structures of civil society. The level of cooperation in a territory contributes to the creation of the social fabric, citizens' networks and more extensive collaboration systems. These are capable of providing their own responses and making their own initiatives in cultural life, outside of the roles of the public administrations. Cooperation between cultural agents enables them to offer more programmes and a better range of activities, and to improve efficiency from the perspective of proximity or action in a certain space.

- In addition to the cultural agents and the administrations, territories can witness the convergence of a large number of actors who are directly or indirectly related to the cultural sector, having a noticeable influence on the contributions and gains. Similarly, we may see cooperation with other sectors that have an influence on the cultural life of a territory. We refer here to the relationship between education and culture, tourism and culture, the environment and culture, social cohesion and culture, etc. Based on cooperation processes, these relationships influence the possibilities of the cultural sector as well as culture's influence on other fields. Despite the evidence, this type of cooperation was transcendent for the democratisation of

\section{Foreign cultural actions}

are understood as the

projection of the culture

(or cultures) of a diverse

country into international

spaces. 
culture, with direct repercussions on citizens, and it represented a very important development factor in the democratisation of post-dictatorship Spain.

\section{International cultural cooperation Foreign cultural actions}

Generally speaking, these are taken to be the various interventions, programmes and endeavours that are carried out in the framework of foreign policy. They also include the functions of a country's diplomatic representatives, as realised in order to promote its culture beyond its own borders. This responsibility requires coordinated participation from ministries of foreign affairs (chancelleries) and ministries of culture; otherwise it can sometimes lead to permanent problems in many countries, as demonstrated by the debates and changes in their structures. Likewise, there is a debate on the function of cities and regions in the desire to put foreign cultural policy into practice.

Foreign cultural actions are understood as the projection of the culture (or cultures) of a diverse country into international spaces. Cultural actions are carried out through cultural embassies, cultural centres and other bodies in foreign countries. They are organised via a set of activities and endeavours which enable the image of a country's culture to be presented to a globalised world.

The cultural actions of embassies facilitate cultural management by those responsible for culture, offering cultural products that circulate around various countries. This creates a network of bilateral cultural exchanges. The intention is to produce permanent coordination between the various ministries and governmental departments which influence the country's foreign presence.

It channels the expressions, with their different forms and languages, of the country's cultural institutions and organisations in order to attain a greater level of internationalisation in cultural actions. To achieve this, it is important for governmental structures to bear in mind the reality of the cultural sector, the cultural agents of the territory and everything that is representative of internal cultural life. There is a danger that foreign cultural actions are only taken to be the actions of the top levels of state or those of certain cultural groups.

\section{International cultural relations}

Cultural action was an instrument in the service of official diplomats, used by states for their relations and approaches in their contacts and agreements that accompanied the diplomatic relations. But nowadays, this point of view has been expanded by new perspectives and possibilities, by the value and contribution of culture to a better comprehension of the "other," with this becoming an essential aspect to incorporate into international relations. International cooperation facilitates the mutual understanding of different cultures and it creates the conditions for pacific co-habitation and greater exchange between citizens and civil societies. Cultural cooperation goes beyond foreign cultural actions with the objective of acting together so as to foster knowledge and respect for otherness, based on trusting relationships which facilitate peaceful cohabitation in international cultural spaces.

But these practices call into question the exclusivity of the state's role in cultural cooperation, whose actions have increased with the emergence of new civil and private organisations which act within the field of international relations, at the margins or in parallel with official articulations. This fosters lighter bilateral nexuses and it forms artistic and cultural networks which act, in certain cases and situations, more spontaneously, quickly and efficiently. Cultural cooperation enables citizens to participate more, thus becoming a very important value in integration processes. This can be observed when considering its function in various international encounters. Said process is shown by new communication and travel possibilities, as well as in the states' loss of exclusivity in international relations. It is also inscribed in the emergence of a new side of international cultural cooperation which must be adapted to said changes and possibilities.

The encouragement of cultural cooperation as a vehicle of exchange and mutual recognition between countries and their cultures. Shared actions via the bidirectional flow of culture, allowing a greater understanding of the other and the cultural relations between civil societies. We understand cultural cooperation as an equitable and egalitarian relationship with expressive forms that serve the purpose of the cultural enrichment of our societies. Cultural cooperation must become a tool for approaching and respecting, complementing other types of international relations. It pursues recognition of the other and shared development in order to guarantee cultural diversity as the heritage of humanity, as proposed by UNESCO.

- $\quad$ Culture is an essential element in the development of a comprehensive international cooperation policy which is in accordance with the demands of the current situations. We must not forget 
that the majority of conflicts and international problems stem from an increasingly evident cultural component which, on occasion, is not incorporated into the political analysis. In this respect, foreign action policy is supplemented and enriched with the fostering of international cultural cooperation.

- International cultural cooperation is a subject that involves all social agents (public administrations, the private sector and civil society) and the government's function within it is to facilitate, stimulate and encourage. This means that platforms and networks for dialogue must play a very important role.

- We understand international cultural cooperation as a set of exchanges that can include real channels for the circulation of cultural realities in both directions. This generates encounters and continuous dialogue via various agreements and conventions in the field of culture and science.

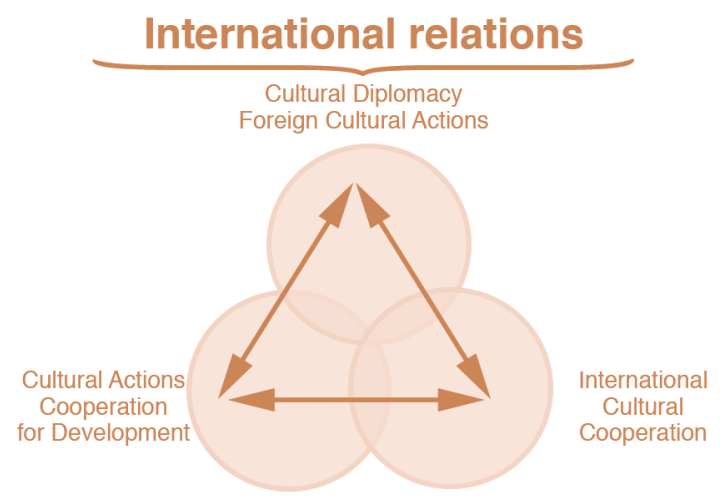

Internacional cooperation

Fig. 2

\section{Cooperation for development and culture}

Beyond the different definitions and concepts of development in a contemporary context, as can be found in various documents and publications, it is important to address the characteristics of the relationship between culture and development. Questions about the contribution of culture to development and to the Millennium Development Goals have been asked in many ways which we can analyse. This is based on what we have called the added value of culture for development or the specific and differing impacts that this field has had on the completeness of development.

Culture has great symbolic value as an expression of identity and lifestyle. "Culture can be considered as the set of distinct, spiritual, material, intellectual and emotional traits that characterise a society or social group. It also includes art, literature, lifestyles, fundamental human rights, systems of values, traditions and beliefs."

Therefore, it is the way in which a society expresses itself and situates its cultural life in a globalised society. It seeks respect for its unique aspects and diversity, based on the principles we find in various declarations from the international community.

Policies that recognise cultural identities and favour diversity do not cause fragmentations, conflicts or authoritarian practices, nor do they reduce the rhythm of development. These policies are viable and necessary, given that the usual source of tensions is the elimination of groups that identify themselves by way of their culture. The recovery and maintenance of cultural identities, and their contact and exchanges with other cultures, based on respect for cultural liberty, are the preconditions of developmental processes. Nobody can be unaware of the difficulty of identifying and objectifying these preconditions, but it is clear that they exist as the essence for the fostering of positive social dynamics which influence development.

Cultures and the effects of cultural life very clearly affect what have been called "intangible values" and these have a great impact on all aspects of political and social life. Cultures give "added value" to the configuration of citizenship, through cultural life that includes: popular expressions in celebrations and traditions, the experience of the recovery of public spaces, cohabitation with a community and numerous services, etc. These are social activities and experiences that facilitate social cohesion and citizens' dignity. They also influence governability as a development factor and the search for common wellbeing. The reduction of the cultural exclusion of social groups and the defence of the concept of "cultural liberty," as cited in the 2004 UNDP report as an element of the defence of identity, is the basis for more involving policies which influence the basic conditions for achieving the Millennium Development Objectives.

Education and culture provide basic elements for the generation of individual and collective skills, and they affect other sectors by contributing to the development resulting from cooperation systems. The function of creativity, the stimulation of expressiveness, the search for quality and 
excellence in culture all influence innovation processes which enable a greater exploitation of the potential of a social reality for the appropriation of its own development processes or the resolution of its problems. Many cultural programmes find great difficulties when calculating and measuring these impacts, which in turn are very important in the results of other fields and which we cannot forget or depreciate in the face of the seduction of other variables which are presented more empirically.

Studies and research into the economy of culture and the study of the cultural sector as a "cluster" have shown very clear results about the role of culture as an economic and social sector. These lines of work have provided research which has analysed and assessed the participation of culture in each country's GDP or satellite accounts, based on the various indicators and the available sources of information which are still very limited.

The cultural sector has specific weight in the field of development policies, without depreciating the intangible and the consideration that culture is transversal within development. Another such consideration is that the cultural life of a community, based on the creation, production and dissemination of cultural assets has large repercussions, due to its symbolic value, but also as a factor of economic growth. Cultural businesses and industries can represent a very important dynamic in some countries, in what some call the management of creativity itself. In this respect, programmes that have helped the cinema, publishing, music and recording industries, as well as the artisanal, design and fashion sectors have shown very significant results.

The activities of the cultural sector have a strong impact on local economies and are capable of creating employment with very specific characteristics. As Greffe reflected in 1999: the evaluation of cultural employment requires us to consider that which is thought of the cultural activities themselves, but non-cultural employment must be added to cultural activities and cultural employment to non-cultural activities. This expresses the difficulties in its quantification but its impacts highlight the fact that cultural life can contribute to the dynamics of development and economic growth in contemporary society, if we make the most of its full potential.

It is clear from the foregoing reflections that cultural life generates indirect impacts in other sectors or activities which in turn add value to that which is cultural, allowing the development of very clear contiguous sectors. A clear example of this can be seen in tourism, not only in what has been called cultural tourism but in the conversion of various patrimonial assets of culture (museums, archaeological sites and remains, architecture, folklore, traditional celebrations, etc.) into tourist destinations which complete the range of activities on offer in this industry. Likewise, we can also consider the attraction of visitors to cities with a high cultural component, etc.: the impact of these would not be possible without certain public cultural policies which support the restoration and maintenance of cultural heritage, as part of a wide and comprehensive vision. But we can also highlight the indirect effects of culture in its contribution to the creation of safer spaces for citizens through the recovery and use of public spaces. This is done via the installation of cultural equipment or programmes in older, degraded areas or in marginal or abandoned areas.

The dynamics that are likely to generate development circulate all around the various contributions of culture, with this encompassing both the more classic concepts of traditional values and lifestyles that are vitally important in some contexts, and also the new face of highly globalised societies which combines local processes with high levels of cultural mobility in contemporary situations. These new visions enable us to continue specifying political programmes and international cooperation projects that can help the Development Assistance Committee member states on a possible path to finding, within their own cultural identities, forms of cohabitation and modernisation. They must find these to satisfy the cultural needs of their citizens and to make use of the chances for improving their opportunities to have an impact on basic under-development problems.

\section{Impacts or effects of culture from the point of view of development}

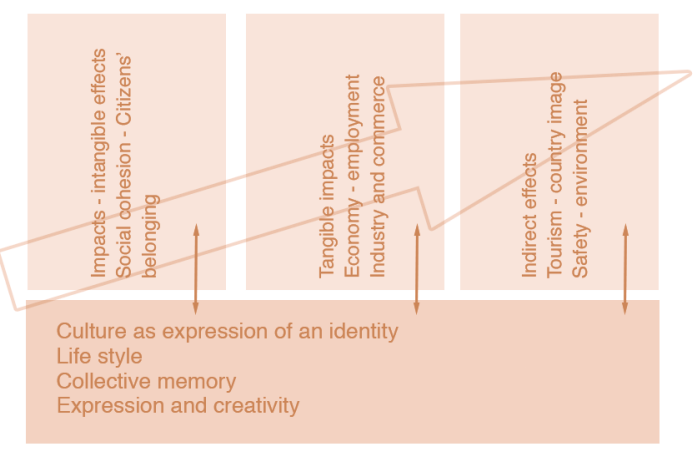

Fig. 3 


\section{How is the cultural dimension specified in development?}

Based on all the international level precedents, the cultural dimension of development has always been present in one form or another in the realities of cultural communities or societies. It has become incorporated thanks to varied and wide-ranging actions and cooperation which different social actors have being carrying out within the framework of their functions.

People, communities, societies and countries have always maintained a level of cultural action which, due to its own dynamics, has contributed to development. Furthermore, other fields and sectors of development policies (education, healthcare, gender, governability, etc.) have always considered culture as a vector to be born in mind, giving it more or less unequivocal consideration. In the majority of cases, the dynamism of local action is one of the characteristics of the incorporation of culture into development aspects.

Perhaps the most determining factor in specifying cultural interventions that emphasise development is found in the analysis of the intentionality of a policy, whether it is public, private or from the third sector.

There are standpoints which considered native or traditional cultures as impediments to progress, economic growth and therefore development. These were more prevalent decades ago but still persist in some hidden attitudes.

There are also passive standpoints which overstress the importance of culture using rhetoric, with very nationalistic points of view or identities that are defensive but manifestly passive in their failure to incorporate culture into political priorities, in their respect for cultural liberty and in their decisions to provide minimal economic resources.

Moving to more proactive standpoints, through the channel of development planning with the incorporation of all aspects of culture, as based on explicit political decisions; these allow cultural life to be placed as the focus point of development and social participation.

Lastly, we cannot forget the great importance of the individuals, groups, communities, social organisations, NGOs, etc. who form what is known as civil society and who maintain a commitment to culture in support of their cultural values. Many cultures owe their permanence to these cooperation processes that go beyond the interventions carried out by the various departments of the state or international organisations.
We believe that these four levels coexist in reality with more or less influence on international cooperation in the field of culture and development. Some of them coexist in the space and time of a certain context and form social capital that is capable of assuming development through cultural life. But the most important aspect to highlight is the efforts made through ascending or descending dynamics to achieve synergies and agreements for development policies through culture, based on consensus, complementarities and respect for cultural liberty.

Based on these considerations and the theoretical frame of reference, it is important to present some forms of organisation in which the presented thoughts may coincide. Within the great variety of possibilities, we could specify the following organisational elements:

- The social and cultural organisations of communities which maintain a vocation for participation in cultural life are structured so as to manage creativity, artistic expression, lifestyles, traditions, the preservation of collective memory and cultural heritage, the cultural education of new generations, etc. This is based on their own plans, with or without the support of governmental authorities, international cooperation or similar organisations. These organisations interpret collective needs and respond appropriately with their actions, depending on the available resources, channelling entrepreneurship from a wide sector of civil society. Their ends may be different but they influence the maintenance of cultural identities and a cultural life that aligns with their options within a framework of freedom.

- Development plans can be established through different governmental departments at a local, regional or national level, as the expression of public policies that respond to the problems of their context. These plans can be incorporated into the cultural dimension as another core of their vocation or they can ignore it. Likewise, some governmental establishments decide to produce specialised strategic plans within the field culture, in order to more vigorously highlight and reinforce the differential aspects which culture contributes to development. This leads to greater effectiveness of all the potentials of their social reality. 


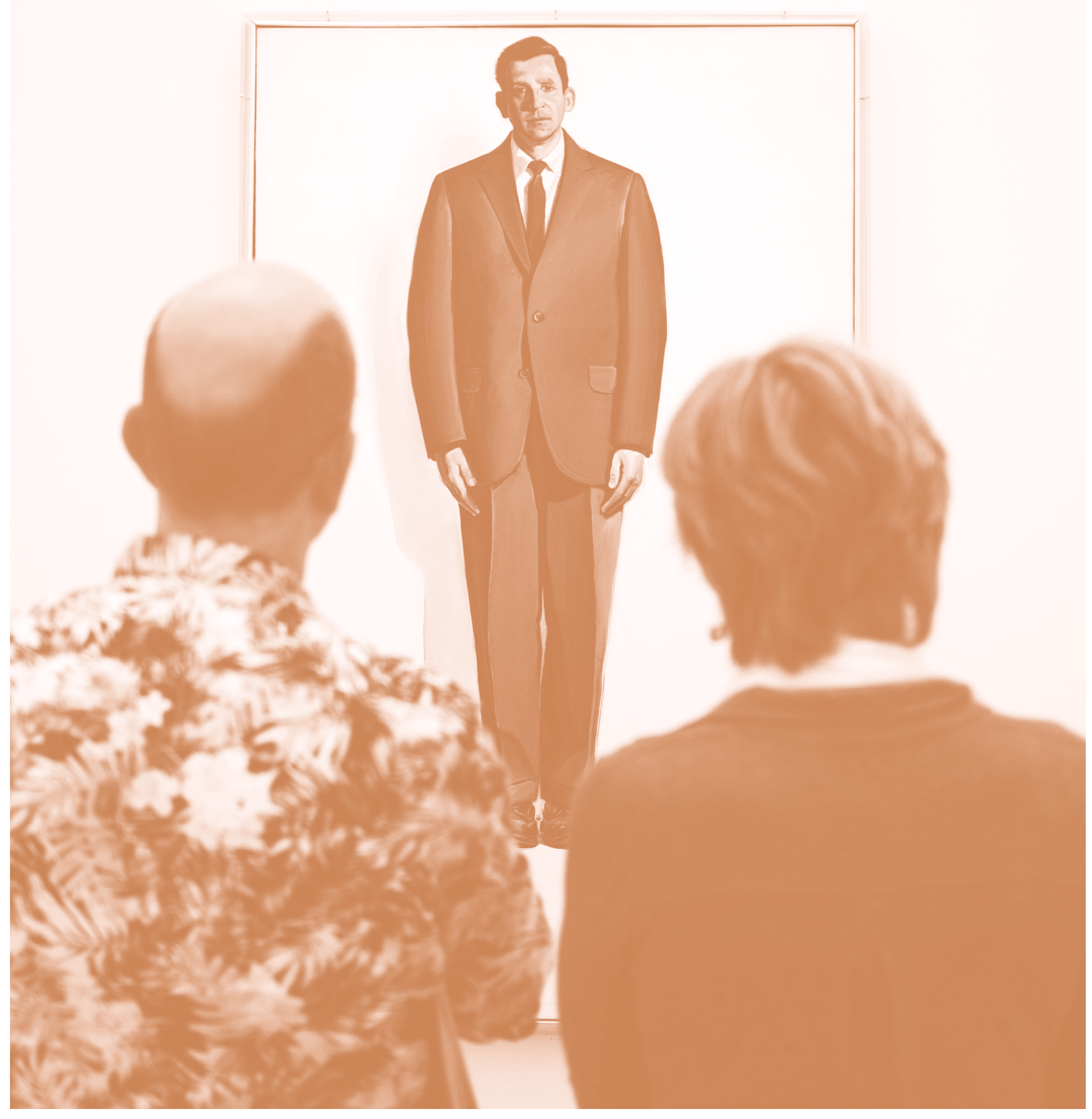


- Similarly, the functions of multilateral bodies include the establishment of programmes in which culture is incorporated into more general plans or specific cultural programmes such as certain funds within the priorities of their institutional mandates.

- In the field of international cooperation for development, some donating countries, as we have seen, establish specific strategies within the field of culture and development, as part of their priorities for negotiation with the member states. Likewise, these countries foster international cooperation based on more involvement from their cultural sector, in defence of cultural diversity, cultural exchange and mutual recognition between cultures. They also favour the participation of certain countries' cultures in broader spaces and markets for the dissemination of their cultural activity and the projection of their creativity.

This extensive set of possibilities is weaving the practices and structures through which are constructed the current models of programmes and projects for cooperation between culture and development, based on the standpoints and guidelines which have been built over these last decades.

Without intending to exhaust all the possibilities, the majority of current practices in specific, culture-based projects are being developed in the following fields:

- The cultural training of the general population so as to encourage individual and collective abilities, so that it can take on the management of its own cultural life.

- The protection, recovery, restoration and addition of value to both material and immaterial cultural heritage, i.e. traditions, celebrations, folklore, etc.

- The recovery of a collective's memory, the study of its own history and forebears so as to reinforce its cultural identities.

- The structuring of cultural governance in accordance with lifestyles, guaranteeing the defence of general interests and the public service of cultural goods and services.

- The configuration of national and international legal statutes that safeguard culture (patrimonial assets, protection of copyrights, defence of historic archives, etc.) or strengthen its possibilities (audiovisual, access to international markets, external projection, the media, etc.).

- The conservation, study and projection of minority or threatened languages.

- The incorporation of the cultural dimension into the educational system so as to raise awareness of the value of cultural diversity.

- The encouragement of artistic training into the various expressive disciplines that represent cultural life. This stimulates creativity and new forms of learning in artistic languages.

- Help in the configuration of the cultural sector within a country's economy. This encourages cultural businesses and industries and access to international markets.

- The strengthening and protection of artists, creators and cultural entrepreneurs, as the drivers of development and the creation of employment.

- The strengthening of independent processes for the management of different media outlets on different supports.

- The defence of the cultural rights of citizens and processes for helping the most vulnerable cultural communities.

- Help for participation in international settings in defence of one's interests and the projection of culture.

\section{Elements and actors in cultural cooperation}

The implementation and management of cultural cooperation processes in general requires a series of elements, actors and abilities that need to be analysed. Cultural management must have mechanisms for identifying the reality of its field of action and for evaluating its situation so that decisions can be made.

We could affirm that the morphology of cultural cooperation requires certain components depending on its context and these can be summarised thusly:

- The need for the presence of various social and cultural agents who are the protagonists in the cooperation processes (see the cultural agents unit).

- The reality of each country's legislative/legal framework, as the expression of the existence of facilities, rights and guarantees for freedom of cultural cooperation. 
- The level of implementation, within the territory, of the cooperation initiatives and actors, as well as compensatory mechanisms for areas that are on the periphery or isolated. The level of mutual recognition between agents.

- Cooperation is not possible without a project mentality. The existence of all types of cultural projects is the highest expression of cultural cooperation.

- The availability of a capacity for cooperation management, based on processes of agreement, consensus, bargaining, co-management, coproduction, etc.

- The capacity for work on the information and communication networks of contemporary society.

- The existence of open access information systems and transparency regarding resources, data, etc.

It is important to have an intense debate on the need to delve into broader and more open cooperation processes between people, territories, countries and cultures. Perhaps now is the time to find new practices for a new context, as stated by Castells: "We have entered a truly multicultural and inter-dependent world that can only be understood and changed from a plural perspective which articulates cultural identity, global interconnection and multidimensional politics."

\section{For Reflection}

As we have seen, cultural cooperation is at the centre of cultural life and the exercise of fundamental rights as human activity.

Cultural management influences widespread cooperation processes offered by culture, making it a fundamental element for professional practice and for situating the principles and values of culture in contemporary society.

Furthermore, cultural cooperation in international relations is another area of action and reflection that is gaining importance due to the great dynamism of global cultural citizens in their cooperation processes. Likewise, the changes in our societies are highlighting the crisis of the classic states in their approach to the possibilities of assuming their roles in the current context.

All of this is a very important matter for reflection for cultural managers to understand their new responsibilities that they must take on in the future. 